\title{
Care provided and care setting transitions in the last three months of life of cancer patients: a nationwide monitoring study in four European countries
}

\author{
Winne Ko ${ }^{1 *}$, Luc Deliens ${ }^{1,2}$, Guido Miccinesi ${ }^{4}$, Francesco Giusti ${ }^{4}$, Sarah Moreels ${ }^{5}$, Gé A Donker ${ }^{6}$, \\ Bregje Onwuteaka-Philipsen ${ }^{3}$, Oscar Zurriaga ${ }^{7,8}$, Aurora López-Maside ${ }^{7}$, Lieve Van den Block ${ }^{1,9}$ \\ and on behalf of EURO IMPACT
}

\begin{abstract}
Background: This is an international study across four European countries (Belgium[BE], the Netherlands[NL], Italy [IT] and Spain[ES]) between 2009 and 2011, describing and comparing care and care setting transitions provided in the last three months of life of cancer patients, using representative GP networks.

Methods: General practitioners (GPs) of representative networks in each country reported weekly all non-sudden cancer deaths (+18y) within their practice. GPs reported medical end-of-life care, communication and circumstances of dying on a standardised questionnaire. Multivariate logistic regressions (BE as a reference category) were conducted to compare countries.

Results: Of 2,037 identified patients from four countries, four out of five lived at home or with family in their last year of life. Over $50 \%$ of patients had at least one transition in care settings in the last three months of life; one third of patients in BE, IT and ES had a last week hospital admission and died there. In the last week of life, a treatment goal was adopted for $80-95 \%$ of those having palliation/comfort as their treatment goal. Cross-country differences in end-of-life care provision included GPs in NL being more involved in palliative care (67\%) than in other countries (35\%-49\%) (OR 1.9) and end-of-life topics less often discussed in IT or ES. Preference for place of death was less often expressed in IT and ES (32-34\%) than in BE and NL (49-74\%). Of all patients, 88-98\% were estimated to have distress from at least one physical symptom in the final week of life.
\end{abstract}

Conclusion: Although palliative care was the main treatment goal for most cancer patients at the end of life in all four countries, frequent late hospital admissions and the symptom burden experienced in the last week of life indicates that further integration of palliative care into oncology care is required in many countries.

\section{Background}

While survival rates for cancer have increased considerably, it is still one of the leading causes of death in many developed countries $[1,2]$. For people suffering from an advanced form of cancer, palliative care is recognised as the preferred form of care at the end of life (EOL). The World Health Organisation (WHO) defines palliative

\footnotetext{
* Correspondence: winne.ko@vub.ac.be

'End-of-Life Care Research Group, Vrije Universiteit Brussel (VUB), Brussels and Ghent University, Ghent, Belgium
}

Full list of author information is available at the end of the article care as 'an approach that improves the quality of life of patients and their families facing the problems associated with life-threatening illness, through the prevention and relief of suffering by means of early identification and impeccable assessment and treatment of pain and other problems, physical, psychosocial and spiritual' [3]. Within the framework of palliative care, several topics are considered important [4], such as the use of palliative care services, communication, advance care planning and the circumstances of dying. Palliative care has been developed differently in different countries in terms 
of processes, structures, policies and resources that support its delivery [5-7]. However, cross-country populationbased studies aimed at describing these variations in actually delivered EOL care for people with cancer in Europe are scarce $[4,8,9]$. Existing studies are often restricted in the themes covered e.g. pain [10] or place of death [11] or in terms of the study population e.g. hospital or hospice settings $[12,13]$.

Comparative and nationwide EU studies measuring across different care settings and cancer types could inform us on organising palliative care for dying cancer patients. General practitioners (GPs) are highly accessible in Europe and they have a central coordinating role in patient care in most EU countries [14]. GPs can generally provide a good public health perspective on endof-life care in their own country. In this study, we aim to use nationwide networks of GPs in four EU countries (Belgium [BE], the Netherlands [NL], Italy [IT] and Spain [ES]) to describe and compare the medical care process, patient-GP communication processes and the actual circumstances of dying of cancer patients in the four countries studied.

\section{Methods}

\section{Design}

Data were collected within the European Sentinel GP Networks Monitoring End-of-Life Care (EURO SENTIMELC) study, which continuously monitored EOL care via the use of representative networks of GPs in 20092011 in four EU countries: 2009-2010 in Belgium, the Netherlands and Italy, and 2010-2011 in Spain. All countries were sampled nationwide except Spain, where two regions (North: Castilla y León and East: Valencia) were included.

Both the study protocol and an earlier wave of data (2008) comparing deceased cancer patients in Belgium and the Netherlands have been published $[4,15,16]$. Using a mortality follow-back questionnaire design, GPs reported all deaths in their practices (age $\geq 18$ yrs.) on the EOL care provided in the final months of life on standardised forms.

\section{Palliative care in the four countries studied}

Access to palliative care has been recognised as a right in all countries except NLalthough there it is covered by the national health insurance. In all four countries, some type of plan or national guideline for palliative care is available [17]; it is therefore understood that patients in these countries have access to palliative care. However, none of these countries recognise palliative care as a medical specialty and the model of palliative care provision varies. For example, GPs co-ordinate care in Italy and Spain in the primary care settings, while in Belgium the care is often shared in the context of a multidisciplinary team and in the Netherlands palliative care is provided mainly by the GPs in consultation with specialist teams $[7,17]$.

\section{Setting and participants}

In general the GP networks are representative of all GPs in the country in terms of age, gender and geographical distribution. Sentinel surveillance systems of GPs are used to provide information regarding the whole patient population in a country, particularly in countries where general practice is highly accessible. Percentages of the general population covered by the GP sentinel networks are $1.75 \%$ of the total Belgian population, $0.8 \%$ of the Dutch population, $2.2 \%$ in Valencia, $3.5 \%$ of the adult population in Castilla y Leon and $4 \%$ of the Italian population (per health district). For the specific purpose of our study we additionally analysed the representativity of the networks to cover all deaths in the country. These results were published earlier [16] showing that data collected from the GP networks had significant but small differences from available mortality statistics or death certificate studies in terms of age, gender and place of death [16]. In all countries GPs can identify deaths due to cancer and non-cancer and those dying at home as well as in institutional settings. GPs appear to underreport a limited number of deaths ie non-sudden hospital deaths and deaths of people under 65 years in Belgium, and possibly also sudden hospital deaths in all countries [16]. Apart from in Italy, the networks in all countries are existing Sentinel GP networks involved in the surveillance of different health related topics [16]. In 2009, the number of GPs participating in the study were 199 (1.8\%) in Belgium, 59 (0.8\%) in the Netherlands and 149 (4.3\%) in Italy. In 2010, the figures were 189 (1.5\%) in Belgium, 63 (0.8\%) in the Netherlands, 94 (2.7\%) in Italy, and 173 in Spain (114 (3.4\%) in Castilla and León, 59 (3\%) in Valencia).

For this study, we included cancer patients only i.e. cancer as GP-reported 'underlying cause of death', and excluded those judged to have died 'suddenly and totally unexpectedly' by the GP. Nursing home deaths from the Netherlands were excluded since GPs discontinued their care after the transition to a nursing home where care is taken over by elderly care physicians.

\section{Data collection and measurements}

To minimise recall bias, physicians recorded deaths immediately after the patient died. Paper-based forms were administered in Belgium, the Netherlands and Castilla y León, whereas a web-based registration was adopted in Italy and an electronic registry in Valencia. To ensure the quality of data collected, instructions on filling out the form were sent to GPs at the beginning of the year in all countries. Every GP is asked to fill in a weekly, 
standardised registration form, whether or not there was a deceased patient. Where a patient had died during that week, the GP filled in the questions concerning care and dying. Only if GPs registered weekly for 26 weeks or more were their data included in the databases.

GPs answered questions about the final three months of life of deceased patients. These questions were derived from and developed in previous research $[4,16,18,19,20]$. A validated item, the MSAS-GDI, was included in the questionnaire [21]. Other items in the questionnaire had been pre-tested in the pilot studies with experts to increase validity and reliability. Further details can be found in the methodological paper published earlier [16].

Questions were classified into three palliative care domains measuring:

\section{- Medical care processes (last three months} and last week of life): number of GP-patient contacts, transitions between care settings, use of specialist palliative care services, use of GP palliative care, costs and burden of informal caregivers as judged by the GP, treatment goals (cure, life-prolonging, palliative care in the final three months of life), terminal hospital admission (i.e. dying in the hospital) and timing of this admission

- Communication processes:

1. Patient-GP conversations about primary diagnosis, incurability of illness, life expectation, possible medical complications, physical complaints, psychological problems, social problems, spiritual problems, options for palliative care, burden of treatments (options: yes, no, not applicable)

2. EOL preferences for place of death and medical treatment as known to the GP.

- Circumstances of dying in the last week of life

Physical and psychological symptom distress was measured using the Memorial Symptom Assessment ScaleGlobal Distress Index (MSAS-GDI) [21]. GPs estimated:

1. Physical symptom distress: lack of appetite, lack of energy, pain, drowsiness, constipation, dry mouth, difficulty in breathing (dyspnoea) (GPs first indicated the presence of symptoms as yes, no or unknown; if yes, they indicated not at all, a little bit, somewhat, quite a bit or very much)

2. Psychological symptom distress: sadness, worry, irritation, nervousness (GPs first indicated the presence of symptoms as yes, no or unknown; if yes, they indicated rarely occasionally, frequently, or almost constantly).

Basic information about the patient (age, gender, type of malignancy, longest place of residence in the last year and place of death) was also registered by the GPs. Questions were first developed in Dutch and subsequently translated into French and English, and from English to Italian and Spanish through forward-backward procedures [16].

\section{Ethical approval}

In Belgium the protocol of the study was approved by the Ethical Review Board of Brussels University Hospital of the Vrije Universiteit Brussel (2004). In Italy, ethics approval for data collection was obtained from the Local Ethical Committee 'Comitato Etico della Azienda U.S.L. n. 9 di Grosseto', Tuscany (2008). Ethical approval was not required for posthumous collection of anonymous patient data in the Netherlands [22,23] or Spain [24-26]. Patients and GPs remain anonymous to researchers and the institutes.

\section{Statistical analysis}

Descriptive statistics were employed to show the distribution of characteristics of the study population and Pearson's chi-squared tests to detect cross-country differences $(\mathrm{p}<.001)$.

Further multivariate logistic regression analyses (with Belgium as the reference category) were performed to study the cross-country variations in EOL care controlling for differences in place of death, age and sex and, for the analyses regarding circumstances of dying, we additionally controlled for the number of GP contacts in the last week of life. Odds ratios (ORs) and 95\% confidence interval (95\% C.I.) were calculated. All analyses were completed with SPSS20.0 (IBM Corp, Armonk, NY)

\section{Results}

\section{Characteristics of patients}

A total of 2,037 deceased cancer patients were identified from four countries (Table 1). Mean age was 73.1 years. Over $85 \%$ of cancer patients lived at home or with family in their last year of life. In Belgium and the Netherlands, $11 \%$ and $9 \%$ lived in a care home whereas the figure was $3 \%$ in Italy and $4 \%$ in Spain.

Home deaths were more common in the Netherlands (57.9\%) and Spain (51.1\%).Except for the Netherlands (17\%), more than one third of cancer patients died in hospital in all countries (34\%[BE], 38\%[IT] and 35\%[ES]).

\section{Medical care processes at the end of life}

During the last three months of life, GPs had more than three contacts with patients in 23\% (BE), 35\% (ES), $42 \%$ (NL) and 58\% (IT) of cases (Table 2). In all countries, 
Table 1 Characteristics of the study population: non-sudden cancer deaths $(N=2037)$

\begin{tabular}{|c|c|c|c|c|c|}
\hline \multirow[t]{2}{*}{ Characteristics } & \multirow{2}{*}{$\begin{array}{l}\text { Belgium }(N=595) \\
N(\%)\end{array}$} & \multirow{2}{*}{$\begin{array}{l}\text { The Netherlands }(N=335) \\
N(\%)\end{array}$} & \multirow{2}{*}{$\begin{array}{l}\text { Italy }(N=830) \\
N(\%)\end{array}$} & \multirow{2}{*}{$\begin{array}{l}\text { Spain }(N=277) \\
N(\%)\end{array}$} & \multirow[t]{2}{*}{$p$-value } \\
\hline & & & & & \\
\hline Age group & & & & & .156 \\
\hline $18-64$ & $160(27.1)$ & $90(26.9)$ & 195(23.5) & $59(21.3)$ & \\
\hline $65-74$ & $131(22.2)$ & $94(28.1)$ & $210(25.3)$ & $65(23.5)$ & \\
\hline 75-84 & 184(31.2) & 103(30.7) & 257(31.0) & 97(35.0) & \\
\hline 85 or above & $115(19.5)$ & $48(14.3)$ & 168(20.2) & $56(20.2)$ & \\
\hline Mean & 72.5 & 71.9 & 73.6 & 74.2 & \\
\hline Gender & & & & & $<.001$ \\
\hline M & $328(55.1)$ & $177(53.2)$ & $448(54.0)$ & 186(67.6) & \\
\hline $\mathrm{F}$ & 267(44.9) & $156(46.8)$ & $382(46.0)$ & $89(32.4)$ & \\
\hline Types of malignancy & & & & & $<.001$ \\
\hline Lung & 148(24.9) & $80(25.0)$ & 182(26.5) & 53(19.8) & \\
\hline Breast & $51(8.6)$ & $33(10.3)$ & $57(8.3)$ & $11(4.1)$ & \\
\hline Colorectal & $69(11.6)$ & $38(11.9)$ & $102(14.8)$ & 49(18.3) & \\
\hline Prostate & $25(4.2)$ & $23(7.2)$ & $35(5.1)$ & 29(10.8) & \\
\hline Other & $302(50.8)$ & $146(45.6)$ & $312(45.3)$ & $126(47.0)$ & \\
\hline Longest place of residence in the last year & & & & $<.001$ & \\
\hline Home or with family & $516(87.2)$ & $300(90.6)$ & 799(96.5) & 258(95.2) & \\
\hline Care home & $65(11.0)$ & $30(9.1)$ & $21(2.5)$ & $10(3.7)$ & \\
\hline Other & $11(1.9)$ & $1(0.3)$ & $8(1.0)$ & $3(1.1)$ & \\
\hline Place of death & & & & & $<.001$ \\
\hline Home & 196(33.2) & 194(57.9) & $377(45.5)$ & $139(51.1)$ & \\
\hline Nursinghome/Residential home for older people & $71(12.0)$ & 28(8.4) & $41(5.0)$ & $11(4.0)$ & \\
\hline Hospital & 198(33.5) & $58(17.3)$ & $312(37.7)$ & $95(34.9)$ & \\
\hline Palliative Care Unit/Hospice & 122(20.6) & $54(16.1)$ & $94(11.4)$ & 26(9.6) & \\
\hline Elsewhere & $4(0.7)$ & $1(0.3)$ & $4(0.5)$ & $1(0.4)$ & \\
\hline
\end{tabular}

${ }^{a}$ Missing for age group: $n=5$, gender: $n=4$, Type of malignancy: $n=166$, Longest place of residence last year: $n=15$, Place of death: $n=11$.

${ }^{b} x^{2}$ test on cross-country differences.

more than half of cancer patients (between $52.6 \%$ and $69 \%$ ) had at least one transition between care settings in their last three months of life. Specialist palliative care services were used in $37 \%$ of cases in NL, compared with $58 \%, 62 \%$ and $65 \%$ in ES, IT and BE respectively. GP palliative care was provided until death in $67 \%$ of cases in NL, compared with $49 \%, 44 \%$ and $35 \%$ in ES, BE and IT. Five percent of patients in Spain had difficulty in covering costs, differing from $20 \%, 38 \%$ and $43 \%$ in $\mathrm{BE}, \mathrm{NL}$ and IT. From $31 \%$ in NL to $35 \%$ (BE), $42 \%$ (ES) and $78 \%$ (IT) of informal caregivers in the four countries were perceived to be overburdened.

In the last week of life, GPs had more than one contact with patients in two thirds of cases in all countries and $17 \%[\mathrm{NL}]$ to $27 \%$ [ES] of patients were transferred to another setting. Terminal hospital admission was experienced by one in three patients in BE, IT and ES respectively, and by $17 \%$ in NL. These admissions occurred in the last week of life in one out of three cases except in ES where it was 48\%. For all countries, palliative care was the main treatment aim for most patients in the last week of life (about $90 \%$ of patients in BE, NL and ES, and $80 \%$ in IT).

After controlling for differences in patient characteristics, variations in GP contacts in the last three months of life remained significant, as did the use of GP and specialist palliative care services.

\section{Communication processes at the end of life}

In all countries, a large majority of GPs had discussed one or more topics (between $89 \%$ [IT] and 98\% [NL]) (Table 3). Most GPs in NL (95\%) discussed primary diagnosis with patients, compared with $84 \%, 71 \%$ and $66 \%$ respectively in BE, ES and IT. Physical complaints were also frequently discussed (between 83\% [IT] and 96\% $[\mathrm{NL}])$. Over half of patients had conversations with GPs on psychological problems (between 60\% [IT] and 87\% $[N L])$. One out of three patients talked about social 
Table 2 Characteristics of the medical care processes at the end of life

\begin{tabular}{|c|c|c|c|c|c|c|c|c|}
\hline \multirow[b]{2}{*}{ Characteristics } & \multirow{2}{*}{$\begin{array}{l}\text { Belgium } \\
(N=595) \\
N(\%)\end{array}$} & \multicolumn{2}{|c|}{$\begin{array}{l}\text { The Netherlands } \\
(N=335)\end{array}$} & \multicolumn{2}{|c|}{ Italy $(N=830)$} & \multicolumn{2}{|c|}{ Spain $(N=277)$} & \multirow[t]{2}{*}{$p$-value ${ }^{a}$} \\
\hline & & $N(\%)$ & $\mathrm{OR}^{\mathrm{b}}(95 \%$ C.I.) & $N(\%)$ & $\mathrm{OR}^{\mathrm{b}}(95 \%$ C.I.) & $N(\%)$ & $\mathrm{OR}^{\mathrm{b}}(95 \%$ C.I. $)$ & \\
\hline \multicolumn{9}{|l|}{ During the last three months of life: } \\
\hline More than three GP-patient contacts ${ }^{d}$ & $137(23.0)$ & $140(41.8)$ & $2.2(1.6-3.0)$ & $480(57.8)$ & $4.6(3.6-5.9)$ & $98(35.4)$ & $1.7(1.3-2.4)$ & $<.001$ \\
\hline $\begin{array}{l}\text { At least one transition to another } \\
\text { care setting }\end{array}$ & $407(69.0)$ & 173(52.6) & $0.8(0.6-1.2)$ & $534(64.4)$ & $0.9(0.7-1.3)$ & 156(57.4) & $0.7(0.5-1.1)$ & $<.001$ \\
\hline $\begin{array}{l}\text { Specialist palliative care services } \\
\text { initiated }\end{array}$ & $370(65.1)$ & 119(37.0) & $0.2(0.2-0.3)$ & $502(62.7)$ & $1.2(0.9-1.6)$ & $160(57.8)$ & $1.0(0.7-1.4)$ & $<.001$ \\
\hline GP provided palliative care until death & $262(44.0)$ & $219(67.0)$ & $1.9(1.3-2.7)$ & $290(35.0)$ & $0.4(0.3-0.6)$ & 129(49.4) & $0.8(0.5-1.2)$ & $<.001$ \\
\hline Difficult in covering care costs & $92(20.3)$ & 107(38.4) & $2.5(1.8-3.6)$ & $306(42.5)$ & $3.0(2.3-4.1)$ & $11(4.9)$ & $0.2(0.1-0.4)$ & $<.001$ \\
\hline Informal caregivers feeling overburdened & 183(34.9) & 92(30.9) & $0.7(0.5-1.00)$ & $590(77.9)$ & $6.1(4.7-8.0)$ & $99(41.8)$ & $1.1(0.8-1.6)$ & $<.001$ \\
\hline $\begin{array}{l}\text { Palliation as important treatment goal } \\
\text { ( } v \text { curative/prolonging life) }\end{array}$ & $305(58.1)$ & 223(76.4) & $2.2(1.6-3.1)$ & $418(60.9)$ & $1.2(0.9-1.5)$ & $138(63.3)$ & $1.2(0.9-1.8)$ & $<.001$ \\
\hline \multicolumn{9}{|l|}{ During the last week of life: } \\
\hline One or more GP-patient contacts & $448(75.3)$ & 286(85.4) & $1.3(0.9-1.9)$ & $625(75.3)$ & $0.8(0.6-1.1)$ & $178(64.3)$ & $0.4(0.3-0.6)$ & $<.001$ \\
\hline $\begin{array}{l}\text { At least one transition to another } \\
\text { care setting }\end{array}$ & $145(24.7)$ & $56(16.8)$ & $0.9(0.6-1.3)$ & 159(19.5) & $0.8(0.6-1.1)$ & $71(27.4)$ & $1.5(1.1-2.3)$ & 0.002 \\
\hline Terminal hospital admission & 198(33.5) & $58(17.3)$ & $0.4(0.3-0.6)$ & $312(37.7)$ & $1.2(1.0-1.5)^{c}$ & 95(34.9) & $1.1(0.8-1.6)$ & $<.001$ \\
\hline $\begin{array}{l}\text { Admission during last week } \\
\text { (vbefore last week) }^{\mathrm{e}}\end{array}$ & 70(35.7) & $22(38.6)$ & $1.2(0.6-2.2)$ & 100(33.2) & $1.0(0.6-1.4)$ & $44(47.8)$ & $1.8(1.1-3.1)$ & .084 \\
\hline $\begin{array}{l}\text { Palliation as important treatment goal } \\
\text { ( } v \text { curative/prolonging life) }\end{array}$ & $522(91.9)$ & 296(94.9) & $1.4(0.8-2.6)$ & $487(80.0)$ & $0.4(0.3-0.6)$ & 206(89.6) & $0.9(0.5-1.5)$ & $<.001$ \\
\hline
\end{tabular}

Abbreviations: GP general practitioner, OR odds ratio.

Missing data:

During last 3 months of life: more than three GP-patient contacts: $n=1 \%$; at least one transition: $n<1 \%$; specialist palliative care initiated: $n<4 \%$; GPs' provision of pall care until death: $\mathrm{n}<3 \%$; difficult in covering care costs: $\mathrm{n}<18 \%$; informal caregivers feeling overburdened: $\mathrm{n}<11 \%$.

During last week of life: transferred at least once: $\mathrm{n}<3 \%$; terminal hospital admission: $\mathrm{n}<1 \%$; admission during last week: $<68 \%$, palliation as important treatment goal during last week: $\mathrm{n}<16 \%$.

${ }^{a} x^{2}$ test on cross-country differences.

${ }^{b}$ Odd Ratios from multivariate logistic regression models. For these analyses, we compared end-of-life care between patients with cancer in the four countries, with Belgium as the reference category, and adjusted differences in place of death, age, gender and the types of malignancy. Odds ratios in bold are statistically significant at $\mathrm{p}<0.05$.

cPlace of death not controlled for in multivariate analyses.

d median number of contacts during the last three months of lifeacross countries was 3.

${ }^{\mathrm{e}}$ For patients who died in hospitals.

problems with their GPs in IT (35\%) and ES (34\%), compared with $57 \%$ and $70 \%$ in $\mathrm{BE}$ and NL respectively. 'Spiritual problems'was the topic least often discussed in all countries, from about $15 \%$ in IT and ES to $32 \%$ in BE and slightly over half (54\%) in NL. Except in IT (37\%), over two-thirds of GPs in all countries had conversations on the options of palliative care (from 67\% [ES] to $70 \%$ $[\mathrm{BE}]$ and $88 \%[\mathrm{NL}])$.

Other than in NL (74\%), fewer than half of cancer patients expressed a preference for place of death (between $32 \%[\mathrm{IT}]$ and $49 \%$ [BE]). Fewer than one-fifth of patients in ES (14\%) and IT (18\%) indicated at any time a preference about medical treatment, whereas the figures were $41 \%$ and $65 \%$ in BE and NL.

When other factors were controlled for, seven out of 10 of the aforementioned differences remained significant and topics such as the incurability of illness (more in NL, 5.0; less in IT \&ES, 0.3) and options for palliative care (more in NL, 1.6; less in IT, 0.4) were less often discussed in IT and ES than in BE and the NL. The higher frequencies of discussions in NL on preference for place of death (OR 2.3, less in IT \& ES, 0.4) and medical treatment (OR 2.4, less in IT 0.3 and ES 0.2) remained.

\section{Circumstances of dying in the last week of life (Table 4)}

Suffering from physical symptoms was common among cancer patients; from $88 \%$ (IT) to $92 \%$ (BE \& NL) and 99\% (ES) experienced at least one symptom. Over $70 \%$ of the patients in all countries experienced lack of energy, except in ES (57\%). From $64 \%, 87 \%$ to $100 \%$ of patients in respectively in BE, IT and ES were judged to be distressed by at least one psychological symptom, and the figure was $48 \%$ for NL. Respectively $66 \%$ [IT], 75\% [BE], 79\% [SP] and $87 \%$ [NL] of patients in all countries died in their preferred place if their wishes were known to the GP.

Results from multivariate analyses confirmed crosscountry differences on symptoms including pain (more 
Table 3 Characteristics of communication processes at the end of life

\begin{tabular}{|c|c|c|c|c|c|c|c|c|}
\hline \multirow[b]{2}{*}{ Characteristics } & \multirow{2}{*}{$\begin{array}{l}\text { Belgium } \\
(N=595) \\
N(\%)\end{array}$} & \multicolumn{2}{|c|}{$\begin{array}{l}\text { The Netherlands } \\
(N=335)\end{array}$} & \multicolumn{2}{|c|}{ Italy $(N=830)$} & \multicolumn{2}{|c|}{ Spain $(N=277)$} & \multirow[t]{2}{*}{$p$-value ${ }^{a}$} \\
\hline & & $N(\%)$ & $\begin{array}{l}\text { OR } \\
\text { (95\% C.I.) }\end{array}$ & $N(\%)$ & $\begin{array}{l}\mathrm{OR}^{\mathrm{b}} \\
(95 \% \text { C.I.) }\end{array}$ & $N(\%)$ & $\begin{array}{l}\mathrm{OR}^{\mathrm{b}} \\
(95 \% \text { C.I.) }\end{array}$ & \\
\hline \multicolumn{9}{|l|}{ GP-patient conversations about: } \\
\hline Primary diagnosis & $474(84.2)$ & 303(95.0) & $3.1(1.8-5.4)$ & $505(66.4)$ & $0.3(0.3-0.5)$ & 157(70.7) & $0.4(0.3-0.6)$ & $<.001$ \\
\hline Incurability of illness & $416(74.4)$ & 298(94.6) & $5.0(2.9-8.6)$ & $345(46.2)$ & $0.3(0.2-0.4)$ & $95(45.0)$ & $0.3(0.2-0.4)$ & $<.001$ \\
\hline Life expectation & $363(64.5)$ & $282(89.5)$ & $4.1(2.7-6.2)$ & $277(37.0)$ & $0.3(0.2-0.4)$ & $56(27.1)$ & $0.2(0.1-0.3)$ & $<.001$ \\
\hline Possible medical complications & 393(70.1) & $267(86.4)$ & $2.6(1.8-3.9)$ & $441(58.7)$ & $0.6(0.4-0.7)$ & 137(62.8) & $0.7(0.5-0.95)$ & $<.001$ \\
\hline Physical complaints & $514(90.7)$ & $306(95.9)$ & $2.3(1.2-4.4)$ & $632(83.0)$ & $0.5(0.4-0.7)$ & 208(90.4) & $0.9(0.5-1.6)$ & $<.001$ \\
\hline Psychological problems & $416(74.3)$ & 272(86.9) & $2.1(1.4-3.1)$ & $442(59.1)$ & $0.5(0.4-0.7)$ & $146(66.2)$ & $0.7(0.5-0.9)$ & $<.001$ \\
\hline Social problems & $284(56.5)$ & $202(70.1)$ & $1.8(1.3-2.6)$ & $249(34.5)$ & $0.4(0.3-0.5)$ & $63(34.4)$ & $0.4(0.3-0.6)$ & $<.001$ \\
\hline Spiritual problems & 169(32.4) & $156(54.4)$ & $2.1(1.5-2.9)$ & $104(14.4)$ & $0.3(0.3-0.5)$ & $27(14.7)$ & $0.3(0.2-0.5)$ & $<.001$ \\
\hline Options for palliative care & 389(70.0) & $272(88.0)$ & $2.7(1.8-4.0)$ & $267(36.4)$ & $0.2(0.2-0.3)$ & $138(66.7)$ & $0.8(0.5-1.1)$ & $<.001$ \\
\hline Burden of treatments & 397(72.6) & 244(81.6) & $1.6(1.1-2.3)$ & $367(50.0)$ & $0.4(0.3-0.5)$ & 136(68.3) & $0.8(0.5-1.1)$ & $<.001$ \\
\hline Overall: One or more of these topics was discussed & $447(94.1)$ & 259(97.7) & $2.2(0.9-5.4)$ & $586(88.7)$ & $0.5(0.3-0.7)$ & 133(95.7) & $1.2(0.5-2.9)$ & $<.001$ \\
\hline \multicolumn{9}{|c|}{ End-of-lifepreferences----Patient everexpressed a preference: } \\
\hline For place of death & 293(49.3) & $245(73.8)$ & 2.3(1.7-3.1) & $267(32.2)$ & $0.4(0.3-0.5)$ & $85(34.0)$ & $0.4(0.3-0.6)$ & $<.001$ \\
\hline About a medical treatment & $225(40.5)$ & 198(65.1) & 2.4(1.7-3.2) & 118(18.2) & $0.3(0.3-0.4)$ & 29(14.3) & $0.2(0.1-0.4)$ & $<.001$ \\
\hline \multicolumn{9}{|c|}{$\begin{array}{l}\text { Missing data: } \\
\text { Prior to last month: Diagnosis, possible medical complication, psychosocial problems: } n<10 \% \text {; incurability of illness, life expectancy: } n<11 \% \text {; physical problems: } \\
\mathrm{n}<8 \% \text {, social problems; } n<17 \% \text {; spiritual problems, } n<16 \% \text {; options of palliative care, } n<12 \% \text {; Burden of treatment: } n<13 \% \text {; one or more issues } \\
\text { discussed: } n<23 \% \text {. } \\
\text { Preference for place of death: } n<13 \% \text {; preference about medical treatment: } n<17 \% \text {. } \\
\text { a } x^{2} \text { test on cross-country differences. } \\
\text { bOdds ratios from multivariate logistic regression models. For these analyses, we compared end-of-life care between patients with cancer in the four countries, } \\
\text { with Belgium as the reference category, and adjusted differences in place of death, age, gender and the types of malignancy. Odds ratios in bold are statistically } \\
\text { significant at } p<0.05 \text {. }\end{array}$} \\
\hline
\end{tabular}

in IT [2.0] \& ES [3.2]), dry mouth (more in IT [1.6] \& ES [2.3]) and, feeling sad (more in IT [2.6] \& ES [3.4]). Patients in NL were more likely (OR 1.8) and patients in IT (0.6) less likely to die in their preferred location compared with $\mathrm{BE}$.

\section{Discussion}

Overall In all countries, four-fifths of cancer patients lived at home or with family in their last year of life. However, the study shows that transitions between care settings at the end of life are common in all countries i.e. more than half over the last three months of life and between $17-27 \%$ in the last week of life, and one third of patients (except in NL) died in hospital. There was also a substantial amount of cross-country variation in the provision of end-of-life care to cancer patients even though $80-95 \%$ had palliative care as an important treatment goal in their last week of life. While GPs were more strongly involved in palliative care in NL than in other countries, specialist palliative care services were used less often. End-of-life topics were less often discussed and preference for place of death was less often known by the GPs in IT and ES compared with BE and NL. More than $88 \%$ of all patients in all countries were estimated to have distress from at least one physical symptom in the final week of life and more than half of cancer patients from at least one psychological symptom.

\section{Strengths and weaknesses}

Strengths of the study include the administration of an analogous research design across countries and the weekly registration keeping recall bias limited, resulting in a robust four-country database of deaths, comparing actual end-of-life care practices. This information supplements the existing data from death certificates or cancer registries [27], hence can serve as an important basis for organisational planning. However, some limitations should be noted. Selecting GPs as the source of information implies underestimation of certain types of care is possible. Nursing homes were excluded in the Netherlands, therefore elderly cancer patients might be underrepresented, although Dutch nursing homes are mainly occupied by people with neurodegenerative disorders [28]. Variations in medical practices exist across countries [29] and the quality of specialist palliative care services was not measured. Also, the questionnaire was kept short and further details on care provision were not available. Even though GPs could offer a macro view of 
Table 4 Circumstances of the dying process

\begin{tabular}{|c|c|c|c|c|c|c|c|c|}
\hline \multirow[b]{2}{*}{ Variable } & \multirow{2}{*}{$\begin{array}{l}\text { Belgium } \\
(N=595) \\
N(\%)\end{array}$} & \multicolumn{2}{|c|}{$\begin{array}{l}\text { The Netherlands } \\
(N=335)\end{array}$} & \multicolumn{2}{|c|}{ Italy $(N=830)$} & \multicolumn{2}{|c|}{ Spain $(N=277)$} & \multirow[t]{2}{*}{$p$-value } \\
\hline & & $N(\%)$ & $\begin{array}{l}\mathrm{OR}^{\mathrm{b}} \\
(95 \% \text { C.I.) }\end{array}$ & $N(\%)$ & $\begin{array}{l}\text { OR }^{\mathrm{b}} \\
(95 \% \text { C.I.) }\end{array}$ & $N(\%)$ & $\begin{array}{l}\text { OR }^{\mathrm{b}} \\
(95 \% \text { C.I. })\end{array}$ & \\
\hline \multicolumn{9}{|l|}{ Physical symptom distress in last week of life } \\
\hline GP could make estimation ${ }^{c}$ & $520(87.4)$ & 285(85.1) & $0.2(0.1-0.3)$ & $702(84.6)$ & $0.5(0.4-0.8)$ & $231(83.4)$ & $0.8(0.5-1.3)$ & .355 \\
\hline Distress from at least one physical symptom & 412(91.6) & 215(91.9) & $1.1(0.6-1.9)$ & $571(88.4)$ & $0.7(0.4-1.1)$ & 134(98.5) & $5.8(1.4-24.8)$ & .002 \\
\hline Lack of appetite & $280(60.1)$ & 120(49.6) & $0.7(0.5-1.0)$ & 299(47.8) & $0.6(0.4-0.8)$ & $67(49.6)$ & $0.7(0.4-0.992)$ & .001 \\
\hline Lack of energy & $344(72.0)$ & 186(73.5) & $1.1(0.8-1.7)$ & $482(73.8)$ & $1.0(0.8-1.3)$ & $83(56.8)$ & $0.5(0.3-0.8)$ & .001 \\
\hline Pain & $93(23.7)$ & $56(26.8)$ & $1.4(0.9-2.2)$ & $236(38.2)$ & $2.0(1.5-2.8)$ & $46(48.4)$ & $3.2(2.0-5.2)$ & $<.001$ \\
\hline Feeling drowsy & $142(32.9)$ & $60(29.0)$ & $1.0(0.7-1.5)$ & 182(29.4) & $0.9(0.7-1.2)$ & $18(25.0)$ & $0.6(0.3-1.1)$ & .438 \\
\hline Constipation & $57(17.8)$ & $22(13.8)$ & $0.7(0.4-1.3)$ & $158(27.7)$ & $1.7(1.2-2.4)$ & $26(32.1)$ & $2.1(1.2-3.8)$ & $<.001$ \\
\hline Dry mouth & $73(20.4)$ & $44(22.6)$ & $1.1(0.7-1.7)$ & 177(30.9) & $1.6(1.1-2.2)$ & $34(39.5)$ & $2.3(1.3-3.8)$ & $<.001$ \\
\hline Difficulty breathing & $140(36.2)$ & $58(32.8)$ & $1.1(0.7-1.6)$ & $243(40.6)$ & $1.3(1.0-1.8)$ & $40(60.6)$ & $2.5(1.4-4.4)$ & $<.001$ \\
\hline \multicolumn{9}{|l|}{ Psychological symptom distress in last week of life } \\
\hline GP could make estimation ${ }^{c}$ & $487(81.8)$ & 258(77.0) & $0.2(0.1-0.3)$ & $649(78.2)$ & $0.6(0.3-1.1)$ & 208(75.1) & $0.7(0.5-1.1)$ & 0.096 \\
\hline Distress from at least one psychological symptom & $241(63.9)$ & $75(48.4)$ & $0.5(0.4-0.8)$ & $341(87.2)$ & $4.2(2.8-6.3)$ & $90(100)$ & Notestim. & $<.001$ \\
\hline Feeling sad & 143(38.0) & $42(25.1)$ & $0.7(0.4-1.0)$ & $247(58.9)$ & 2.6(1.9-3.6) & $57(67.1)$ & $3.4(2.0-5.8)$ & $<.001$ \\
\hline Worrying & 162(41.9) & $50(29.9)$ & $0.7(0.4-1.0)$ & $164(41.7)$ & $1.0(0.7-1.3)$ & $54(63.5)$ & $2.2(1.3-3.7)$ & $<.001$ \\
\hline Feeling irritable & $87(25.9)$ & $11(8.7)$ & $0.3(0.1-0.6)$ & $145(42.0)$ & $2.1(1.5-3.0)$ & $18(54.5)$ & $3.5(1.6-7.5)$ & $<.001$ \\
\hline Feeling nervous & 116(33.0) & $16(11.8)$ & $0.3(0.2-0.5)$ & $146(42.6)$ & $1.6(1.2-2.3)$ & $22(46.8)$ & $1.7(0.9-3.3)$ & $<.001$ \\
\hline Died at the place of wish ${ }^{d}$ & $221(75.4)$ & $214(87.3)$ & $1.8(1.1-2.9)$ & $176(65.9)$ & $0.6(0.4-0.8)$ & $67(78.8)$ & $1.2(0.6-2.1)$ & $<.001$ \\
\hline
\end{tabular}

Missing data:

Physical symptoms were measured on five levels in the original questionnaire (not at all, a little bit, somewhat, quite a bit or very much), variables were later recoded into two categories: quite a bit and very much vs all others; Missing values for physical symptoms Distress from at least one physical symptom: $\mathrm{n}<29 \%$; Physical symptoms: lack of appetite: $\mathrm{n}<28 \%$; lack of energy: $\mathrm{n}<26 \%$; pain: $\mathrm{n}<17 \%$; drowsy: $\mathrm{n}<19 \%$; constipation: $\mathrm{n}<21 \%$; dry mouth: $\mathrm{n}<22 \%$; difficulty breathing: $\mathrm{n}<19 \%$.

Psychological symptoms were measured on four levels in the original questionnaire (rarely, occasionally, frequently or almost constantly), variables were later recoded into two categories: frequently and almost constantlyvs all others; Distress from at least one psychosocial symptom: $\mathrm{n}<51 \%$; Psychosocial symptoms: feeling sad: $n<49 \%$, worry: $n<50 \%$, irritable: $n<59 \%$, nervous: $n<57 \%$.

Died at the preferred place of wish: information available for $44 \%$ of the patients.

${ }^{a}{ }^{2}$ test on cross-country differences.

${ }^{b}$ From multivariate logistic regression models. For these analyses, we compared end-of-life care between patients with cancer in the four countries, with Belgium as the reference category, and adjusted differences in place of death, age, gender, types of malignancy and the number of GPs contact in the last week of life. Odds ratios in bold are statistically significant at $p<0.05$.

${ }^{\mathrm{c}}$ For at least one symptom.

${ }^{d}$ If the wish of the patient was known to the GP. For the death at the place of wish, we adjusted differences in the longest place of residence, number of GPs contact in the last week of life, age, sex and types of malignancy.

the end-of-life care received by their patients, caregiverreported outcomes might be more accurate for some items such as caregiver burden and patients' psychological symptoms in the last week of life. Currently these items were based on 'GPs' perception' after death, and therefore should be interpreted with caution as GPs might under/over-estimate the burden of care.

\section{Common challenges in end-of-life care}

One important common challenge concerns transitions between care settings, which were common during both the final three months (more than half in all countries) and the last week (between one in six and one in four cases) of life. A considerable number of patients (from a third to half) continued to be admitted to hospital in the last week of life and eventually died there. One third or more of informal caregivers of cancer patients were perceived as being overburdened (between 31\% and 79\%).

Transitions between care settings and terminal hospital admissions are incongruent with the wishes of most patients to die in familiar surroundings and may not only adversely affect the quality of care and the quality of dying of the patient [30-33] but also influence the quality of life of informal caregivers [34,35]. Although it is unclear from our study why these transitions took place, the results do show that all countries, though the Netherlands least, are struggling to meet most cancer patients' preferences for dying at home, often due to late hospital admissions. While most palliative care policies of EU countries advocate avoiding hospital death, these results call for the need to understand how this goal can be attained. 


\section{Cross-country differences in palliative care provision and end-of-life communication}

Palliative care is organised differently in each of the four countries [7] and our results demonstrate large variations in the care delivered in the final three months. The Netherlands showed a lower percentage of specialist palliative care provision (one third vs. half or more in the other countries) and a stronger GP role in providing endof-life care for cancer patients. In other countries, the role of specialist palliative care services in counselling regular caregivers is more pronounced in the final months of life. The emphasis on GPs being the primary palliative care providers in the Netherlands [36,37] -noticeably in education and policy - might be a possible explanation for this difference. Existing research showed that in some cases the involvement of specialist palliative care [38] might increase the proportions of home death, but this cannot be verified by our existing data. These differences might also be related to cultural, legal, societal and organisational variations in care [39-41]. Future studies need to shed light on the interplay between these factors to explain the variations we found.

GPs in the four countries engaged in conversations with their patients concerning prognosis, spiritual issues, palliative care and other end-of-life care issues to various degrees. This illustrates the huge variations in the topics discussed at the end of life in Europe corresponding with results found in previous studies in several other populations $[17,42]$. While in all countries physical complaints were frequently discussed, in some such as Belgium and the Netherlands incurability of illness and life expectation were also often discussed, which was not the case in Italy or Spain. Though standardisation in communication might not be feasible due to factors like cultural differences, it would be enlightening to find out how GPs in Belgium and the Netherlands approached patients in these difficult conversations [4], for example whether communication guides could increase physician/patient communication [43,44].

Furthermore, while all the four countries we studied affirm palliative care as a right for all patients, due to the differences in existing healthcare systems the content of care differs across the countries. Though the present study could not provide answers about the quality of care received by patients in these countries e.g. satisfaction of family, cost and benefit analyses, differences found in outcomes such as place of death and the number of contacts with patients in the last week of life might reflect the specifics of palliative care organisation, such as strong primary care in the Netherlands and the more frequent use of specialist palliative care in Belgium.

\section{Circumstances of dying}

Although the results concerning symptoms in the last week of life should be interpreted with caution considering that they were rated by GPs rated the symptoms in all countries GPs indicated that there is a high prevalence of symptom distress in the last week of life. This might reflect a common problem of symptom control in all countries. On the other hand, the proportions of missing values for physical and psychological symptoms were higher than other items in the questionnaire, which might reflect the limitation of using GPs in reporting them. Symptoms and distress levels reported by patients themselves are more accurate than those rated by proxies, including GPs, nurses or families. The present study did not include patients reported symptom burden (reporting could be burdensome at the end of life) and thus the results canonly be interpreted as what had been perceived by the caring GPs in the final months of life.

\section{Implications for practice, policy and future research}

The latest EAPC Atlas for Palliative Care [7] brings encouraging news to by illustrating recent changes such as the development of postgraduate courses in Belgian universities, the updated Dutch palliative care guidelines, the growth of palliative care support teams in Italy and a Spanish law (applicable in three regions) affirming citizens' rights to palliative care. Nevertheless, our results revealed that hospitalisations and transitions remain frequent. A lot of cancer patients also had a number of burdensome symptoms at the end of life according to their GPs, which suggests the need for the support of clinicians in assessing the distress of patients. Also, several country-differences became apparent such as in communications and types of palliative care delivery. National palliative care organisations may wish to consider adjusted policies or guidelines for GPs to improve their skills in end-of-life communications and countries could benefit from learning from each other to improve care.

\section{Conclusion}

Although palliative care was the main treatment goal for most cancer patients at the end of life in all four countries, frequent late hospital admissions and the symptom burden experienced in the last week of life indicates that further integration of palliative care into oncology care is required in many countries.

\section{Consent}

Written informed consent was obtained from the patient for the publication of this report and any accompanying images.

\section{Abbreviations \\ GP: General practitioners; ORs: Odd ratios; EOL: End-of-life; WHO: World Health Organisation; BE: Belgium; NL: the Netherlands; IT: Italy; ES: Spain.}

\section{Competing interests}

The authors declare that they have no competing interests. 


\section{Authors' contributions}

WK and LVDB analysed and interpreted the data. All authors were involved in interpreting the data, drafting and revising of the manuscript. LD, GM, FG, SM, GAD, BOP, OZ, ALM and LVDB collected the data and obtained the funding. All authors read and approved the final version of this manuscript.

\section{Acknowledgements}

EURO IMPACT, European Intersectorial and Multidisciplinary Palliative Care Research Training, is funded by the European Union Seventh Framework Programme (FP7/2007-2013, under grant agreement $n^{\circ}$ [264697]). EURO IMPACT aims to develop a multidisciplinary, multi-professional and inter-sectorial educational and research training framework for palliative care research in Europe. EURO IMPACT is coordinated by Prof Luc Deliens and Prof Lieve Van den Block of the End-of-Life Care Research Group, Ghent University \& Vrije Universiteit Brussel, Brussels, Belgium. Other partners are: VU University Medical Center, EMGO Institute for health and care research, Amsterdam, the Netherlands; King's College London, Cicely Saunders Institute, London, Cicely Saunders International, London, and Internationa Observatory on End-of-Life Care, Lancaster University, Lancaster, United Kingdom; Norwegian University of Science and Technology, and EAPC Research Network, Trondheim, Norway; Regional Palliative Care Network, IRCCS AOU San MartinoIST, Genoa, and Cancer Research and Prevention Institute, Florence, Italy; EUGMS European Union Geriatric Medicine Society, Geneva, Switzerland; Springer Science and Business Media, Houten, the Netherlands.

\section{Collaborators EURO IMPACT}

Van den Block Lieve, De Groote Zeger, Brearley Sarah, Caraceni Augusto, Cohen Joachim, Francke Anneke, Harding Richard, Higginson Irene, Kaasa Stein, Linden Karen, Miccinesi Guido, Onwuteaka-Philipsen Bregje, Pardon Koen, Pasman Roeline, Pautex Sophie, Payne Sheila, Deliens Luc.

\section{Author details}

${ }^{1}$ End-of-Life Care Research Group, Vrije Universiteit Brussel (VUB), Brussels and Ghent University, Ghent, Belgium. ²Department of Medical Oncology, University Hospital Ghent, Ghent, Belgium. ${ }^{3}$ EMGO Institute for Health and Care Research, Department of Public and Occupational Health, and Palliative Care Expertise Centre, VU University Medical Centre, Amsterdam, the Netherlands. ${ }^{4}$ Clinical and Descriptive Epidemiology Unit, Cancer Prevention and Research Institute, ISPO, Florence, Italy. ${ }^{5}$ Public Health and Surveillance, Scientific Institute of Public Health, Brussels, Belgium. ${ }^{6}$ NIVEL, Netherlands Institute for Health Services Research, Utrecht, the Netherlands. ${ }^{7}$ Public Health Directorate General, Health Department, Valencia, Spain. ${ }^{8}$ Spanish Consortium for Research in Epidemiology and Public Health, CIBERESP, Barcelona, Spain. ' Department of Family Medicine and Chronic Care, Vrije Universiteit Brussel (VUB), Brussels, Belgium.

Received: 26 March 2014 Accepted: 11 December 2014 Published: 16 December 2014

\section{References}

1. US Cancer Deaths Continue Long-Term Decline. http://www.cancer.gov/ ncicancerbulletin/010813/page5 (accessed 10/6/2013).

2. Malvezzi M, Bertuccio $P$, Levi F, La Vecchia C, Negri E: European cancer mortality predictions for the year 2013. Ann Oncol 2013, 24:792-800.

3. WHO Definition of Palliative Care. http://www.who.int/cancer/palliative/ definition/en/ (accessed 10/6/2013)

4. Meeussen K, Van den Block L, Echteld MA, Boffin N, Bilsen J, Can Casteren V, Abarshi E, Donker G, Onwuteaka-Philipsen B, Deliens L: End-of-life care and circumstances of death in patients dying as a result of cancer in Belgium and the Netherlands: a retrospective comparative study. J Clin Oncol 2011, 29:4327-4334.

5. Smith AK, Thai JN, Bakitas MA, Meier DE, Spragens LH, Temel JS, Weissman DE, Rabow MW: The diverse landscape of palliative care clinics. J Palliat Med 2013, 16:661-668.

6. Mazanec P, Daly BJ, Pitorak EF, Kane D, Wile S, Wolen J: A new model of palliative care for oncology patients with advanced disease. $J$ Hosp Palliat Nurs 2009, 11:324-331.

7. Centeno C, Lynch T, Donea O, Rocafort J, Clark D: EAPC atlas of palliative care in Europe 2013. Full edition. Milan: EAPC Press; 2013.
8. Gao W, Ho YK, Verne J, Glickman M, Higginson IJ: GUIDE_care project: changing patterns in place of cancer death in England: a populationbased study. PLoS Med 2013, 10:e1001410.

9. Gott M, Gardiner, Ingleton C, Cobb M, Noble B, Bennett MI, Seymour What is the extent of potentially avoidable admissions amongst hospital inpatients with palliative care needs? BMC Palliat Care 2013, 12:9.

10. Klepsted P, Fladvad T, Skorpen F, Bjordal K, Caraceni A, Dale O, Davies A, Kloke M, Lundstrom S, Maltoni M, Radbruch L, Sabatowski R, Sigurdardottir V, Strasser F, Fayers PM, Kaasa S, European Palliative Care Research Collaborative (EPCRC); European Association for Palliative Care Research Network: Influence from genetic variability on opioid use for cancer pain: a European genetic association study of 2294 cancer pain patients. Pain 2011, 152:1139-1145.

11. Cohen J, Houttekier D, Onwuteaka-Philipsen B, Miccinesi G, Addington-Hall J, Kaasa S, Bilsen J, Deliens L: Which patients with cancer die at home? A study of sic European countries using death certificate data. J Clin Oncol 2010, 28:2267-2273.

12. Hall S, Davies A: An evaluation of the activity of a 7-day, nurse-led specialist palliative care service in an acute district general hospital. Int J Palliat Nurs 2013, 19:148-150.

13. Maltoni M, Miccinesi $G$, Morino $P$, Scarpi $P$, Bulli F, Martini F, Canzani D, Dall'Agata M, Paci E, Amadori D: Prospective observational Italian study on palliative sedation in two hospice settings: differences in casemixes and clinical care. Support Care Cancer 2012, 20:2829-2836.

14. Gérvas J, Pérez Fernández M, Starfield BH: Primary care, financing and gatekeeping in western Europe. Fam Pract 1994, 11:307-317.

15. Abarshi E, Echteld MA, Van den Block L, Donker G, Bossuyt N, Meeussen K, Bilsen J, Onwuteaka-Philipsen B, Deliens L: Use of palliative care services and general practitioner visits at the end of life in the Netherlands and Belgium. J Pain Symptom Manage 2011, 41:436-448.

16. Van den Block L, Onwuteaka-Philipsen B, Meeussen K, Donker G, Giusti F, Miccinesi G, Van Casteren V, Alonso TV, Zurriage O, Deliens L: Nationwide continuous monitoring of end-of-life care via representative networks of general practitioners in Europe. BMC Fam Pract 2013, 14:73.

17. Evans N, Costantini M, Pasman HR, Van den Block L, Donker GA, Miccinesi G, Bertolissi G, Gil M, Boffin N, Zurriaga O, Deliens L, Onwuteaka-Philipsen B, EURO IMPACT: End-of-life communication: a retrospective survey of representative general practitioner networks in four countries. J Pain Symptom Manage 2014, 47:604-619.

18. Van den Block L, Deschepper R, Bilsen J, Bossuyt N, Van Casteren V, Deliens L: Euthanasia and other end-of-life decisions: a mortality follow-back study in Belgium. BMC Public Health 2009, 9:79.

19. Cartwright $C$, Onwuteaka-Philipsen BD, Williams G, Faisst $K$, Mortier F, Nilstun T, Norup M, van der Heide A, Miccinesi G: Physician discussions with terminally ill patients: a cross-national comparison. Palliat Med 2007, 21:295-303.

20. Hickman SE, Tilden VP, Tolle SW: Family reports of dying patients' distress: the adaptation of a research tool to assess global symptom distress in the last week of life. J Pain Symptom Manage 2001, 22:565-574.

21. Portenoy RK, Thaler HT, Kornblith AB, Leopare JM, Friedlander-Klar H, Kiyasu E, Sobel K, Coyle N, Kemeny N, Norton L, Scher H: The Memorial Symptom Assessment Scale: an instrument for the evaluation of symptom prevalence, characteristics and distress. Eur J Cancer 1994, 30A:1326-1336.

22. Dutch Personal Data Protection Act (Unofficial English translation). http://www.dutchdpa.nl/Pages/en_wetten_wbp.aspx. (accessed 10/6/2013).

23. Wet bescherming persoonsgegevens. http://wetten.overheid.nl/BWBR0011468/ geldigheidsdatum_24-10-2012. (accessed 10/6/2013).

24. Ley $41 / 2002$, de 14 de noviembre, básica reguladora de la autonomía del paciente y de derechos y obligaciones en materia de información y documentación clínica. http://www.boe.es/buscar/doc.php?id=BOE-A-200222188. (accessed 10/6/2013).

25. Ley Orgánica 15/1999, de 13 de diciembre, de Protección de Datos de Carácter Personal. http://www.boe.es/buscar/doc.php?id=BOE-A-1999-23750. (accessed 10/6/2013).

26. Ley 14/1986, de 25 de abril, General de Sanidad. http://www.boe.es/buscar/ doc.php?id=BOE-A-1986-10499. (accessed 10/6/2013)

27. (IOM) loM: Describing Death in America: What We Need to Know. Washington DC: National Academy Press; 2003.

28. Brandt HE, Deliens L, Ooms ME, van der Steen J, ven der Wal G, Ribbe MW: Symptoms, signs, problems, and diseases of terminally ill nursing home patients. a nationwide observational study in the Netherlands. Arch Intern Med 2005, 165:314-320. 
29. Corallo AN, Croxford R, Goodman DC, Bryan EL, Srivastava D, Stukel TA: A systematic review of medical practice variation in OECD countries. Health Policy. [Epub ahead of print] doi:10.1016/j.healthpol.2013.08.002.

30. End-of-life hospital care for cancer patients. Canadian Institute for Health Information; 2013.

31. Smeenk FW, de Witte LP, van Haastregt JC, Schipper RM, Biezemans HP, Crebolder HF: Transmural care. A new approach in the care for terminal cancer patients: its effects on re-hospitalization and quality of life. Patient Educ Counc 1998, 35:189-199.

32. Improving end-of-life care. NIH Consens State Sci Statements 2004, 21:1-28m.

33. Meeussen K, Van den Block L, Bossuyt N, Bilsen J, Echteld M, Van Casteren V, Deliens L: GPs' awareness of patients' preference for place of death. $\mathrm{Br} J$ Gen Pract 2009, 59:665-670.

34. Chen ML, Chu L, Chen HC: Impact of cancer patients' quality of life on that of spouse caregivers. Support Care Cancer 2004, 12:469-475.

35. Wright AA, Keating NL, Balboni TA, Matulonis UA, Block SD, Prigerson HG: Place of death: correlations with quality of life of patients with cancer and predictors of bereaved caregivers' mental health. J Clin Oncol 2010, 28:4457-4464

36. Borgsteede SD, Deliens $L$, can der Wal G, Francke HL, Stalman WA, van Eijk JT: Interdisciplinary cooperation of GPs in palliative care at home: a nationwide survey in The Netherlands. Scand J Prim Health Care 2007, 25:226-231.

37. Groot MM, Vernooij-Dassen MJ, Crul BJ, Grol RP: General practitioners (GPs) and palliative care: perceived tasks and barriers in daily practice. Palliat Med 2005, 19:111-118.

38. Houttekier D, Cohen J, Van den Block L, Bossuyt N, Deliens L: Involvement of palliative care services strongly predicts place of death in Belgium. J Palliat Care 2010, 13:1461-1468.

39. Gysels M, Evans N, Meñaca A, Andrew E, Toscani F, Finetti S, Pasman HR, Higginson I, Harding R, Pool R; Project PRISMA: Culture and end of life care: a scoping exercise in seven European countries. PLoS One 2012, 7:e34188.

40. Jai J, Beavan J, Faull C: Challenges of mediated communication, disclosure and patient autonomy in cross-cultural cancer care. Br J Cancer 2011, 105:918-924.

41. Searight HR, Gafford J: Cultural diversity at the end of life: issues and guidelines for family physicians. Am Fam Physician 2005, 71:515-522.

42. Van der Heide A, Deliens L, Faisst K, Nilstun T, Norup M, Paci E, van der Wal $G$, van der Maas PJ; EURELD consortium: End-of-life decision-making in six European countries: descriptive study. Lancet 2003, 362:345-350

43. You JJ, Fowler RA, Heyland DK: Just ask: discussing goals of care with patients in hospital with serious illness. CMAJ 2014, 186(6):425-432

44. Balaban RB: A physician's guide to talking about end-of-life care. J Gen Intern Med 2000, 15:195-200.

doi:10.1186/1471-2407-14-960

Cite this article as: Ko et al.: Care provided and care setting transitions in the last three months of life of cancer patients: a nationwide monitoring study in four European countries. BMC Cancer 2014 14:960.

\section{Submit your next manuscript to BioMed Central and take full advantage of:}

- Convenient online submission

- Thorough peer review

- No space constraints or color figure charges

- Immediate publication on acceptance

- Inclusion in PubMed, CAS, Scopus and Google Scholar

- Research which is freely available for redistribution

Submit your manuscript at www.biomedcentral.com/submit
Ciomed Central 